\title{
The hippocampus supports multiple cognitive processes through relational binding and comparison
}

\author{
Rosanna K. Olsen ${ }^{1 *}$, Sandra N. Moses ${ }^{1,2,3}$, Lily Riggs ${ }^{1,4}$ and Jennifer D. Ryan ${ }^{1,4,5}$ \\ 1 Ryan Laboratory, Rotman Research Institute, Baycrest, Toronto, ON, Canada \\ 2 Department of Diagnostic Imaging, Hospital for Sick Children, Toronto, ON, Canada \\ ${ }^{3}$ Department of Medical Imaging, University of Toronto, Toronto, ON, Canada \\ ${ }^{4}$ Department of Psychology, University of Toronto, Toronto, ON, Canada \\ ${ }^{5}$ Department of Psychiatry, University of Toronto, Toronto, ON, Canada
}

\section{Edited by:}

Joel Voss, Northwestern University

Feinberg School of Medicine, USA

\section{Reviewed by:}

Joel Voss, Northwestern University

Feinberg School of Medicine, USA

Deborah E. Hannula, University of

Illinois, USA

\section{*Correspondence:}

Rosanna K. Olsen, Ryan Laboratory,

Rotman Research Institute,

Baycrest, 3560 Bathurst Street,

Toronto, ON M6A 2E1, Canada.

e-mail: rolsen@rotman-

baycrest.on.ca
It has been well established that the hippocampus plays a pivotal role in explicit long-term recognition memory. However, findings from amnesia, lesion and recording studies with non-human animals, eye-movement recording studies, and functional neuroimaging have recently converged upon a similar message: the functional reach of the hippocampus extends far beyond explicit recognition memory. Damage to the hippocampus affects performance on a number of cognitive tasks including recognition memory after short and long delays and visual discrimination. Additionally, with the advent of neuroimaging techniques that have fine spatial and temporal resolution, findings have emerged that show the elicitation of hippocampal responses within the first few $100 \mathrm{~ms}$ of stimulus/task onset. These responses occur for novel and previously viewed information during a time when perceptual processing is traditionally thought to occur, and long before overt recognition responses are made. We propose that the hippocampus is obligatorily involved in the binding of disparate elements across both space and time, and in the comparison of such relational memory representations. Furthermore, the hippocampus supports relational binding and comparison with or without conscious awareness for the relational representations that are formed, retrieved and/or compared. It is by virtue of these basic binding and comparison functions that the reach of the hippocampus extends beyond long-term recognition memory and underlies task performance in multiple cognitive domains.

Keywords: relational, binding, comparison, short-delay recognition, visual perception, amnesia, fMRI, MEG

\section{INTRODUCTION}

The realization that the hippocampus may be critical for memory was made evident soon after patient H.M.'s surgery to treat intractable epilepsy, in which the hippocampus was removed bilaterally and he was left with profound and devastating global amnesia (Scoville and Milner, 1957). Since then, the goal of memory researchers has been to precisely characterize the fundamental role of the hippocampal system in memory. Initial studies demonstrated that amnesic patients with hippocampal damage had clear and profound memory impairments when they were asked to remember information for longer than about $30 \mathrm{~s}$ (Sidman et al., 1968; Warrington and Baddeley, 1974). By contrast, amnesic patients were able to remember verbal items over shorter delays (Drachman and Arbit, 1966), were able to learn new skills implicitly (Milner, 1962; Corkin, 1968), and were able to perform normally on non-declarative tasks such as wordcompletion in the absence of conscious awareness for the learning episodes (Graf and Schacter, 1985). Based on these and similar observations, memory theorists posited that the hippocampus is critically involved in explicit long-term recognition memory, but not short-term memory or procedural/implicit learning (Baddeley and Warrington, 1970; Graf and Schacter, 1985;
Schacter, 1987; Cave and Squire, 1992; Squire, 1992). However, this model of hippocampal function may not adequately capture the full range of the hippocampus' contribution to memory, much less to cognition, in general.

More recent findings from human neuropsychological studies, neuroimaging research, and non-human animal studies suggest that the hippocampus participates in a wide range of cognitive processes, well beyond the realm of explicit long-term recognition memory. For example, lesions to the hippocampus result in recognition deficits across a variety of delays (Kesner et al., 1993; Hannula et al., 2006; Nichols et al., 2006; Olson et al., 2006a,b; Hartley et al., 2007; Piekema et al., 2007; Ezzyat and Olson, 2008; Finke et al., 2008; Shrager et al., 2008; Jeneson et al., 2010, 2011), and on a variety of tasks other than explicit long-term recognition (Chun and Phelps, 1999; Ryan et al., 2000) including what are ostensibly considered perceptual discrimination tasks (Lee et al., 2005a; Warren et al., 2011). Finally, converging evidence from neuroimaging has also indicated that the hippocampus is engaged over short-delays (Ranganath and D'Esposito, 2001; Ranganath et al., 2005; Nichols et al., 2006; Piekema et al., 2006; Axmacher et al., 2007; Olsen et al., 2009) and during a time window that is traditionally associated with perceptual processing 
(Riggs et al., 2009). Such findings challenge the traditional view that the hippocampus is strictly involved in explicit long-term recognition memory and suggest that the reach and function of the hippocampus is much broader than previously thought.

We propose that the critical role of the hippocampus is to rapidly, continuously, and obligatorily form associations among disparate elements across space and time, and further, to enable the comparison of internal representations with current perceptual input (Figure 1; Eichenbaum and Cohen, 2001; Ryan and Cohen, 2003; Moses and Ryan, 2006). The binding and comparison processes outlined in this review are more basic in nature than functions that are often ascribed to the hippocampus. As a result, even though the primary evidence for this view has been drawn from the long-term memory literature (for reviews see Cohen et al., 1999; Ryan and Cohen, 2003; Mayes et al., 2007; Konkel and Cohen, 2009), this model of hippocampal function can account for the growing literature that implicates the hippocampus in short-delay recognition and perception. That is, binding and comparison are so foundational that they are relevant to, and can be used in service of, many cognitive operations beyond long-term memory. The hippocampus then becomes critical for any cognitive operation that requires the formation of relational memory representations among multiple stimuli, regardless of whether that operation is tested after a short or

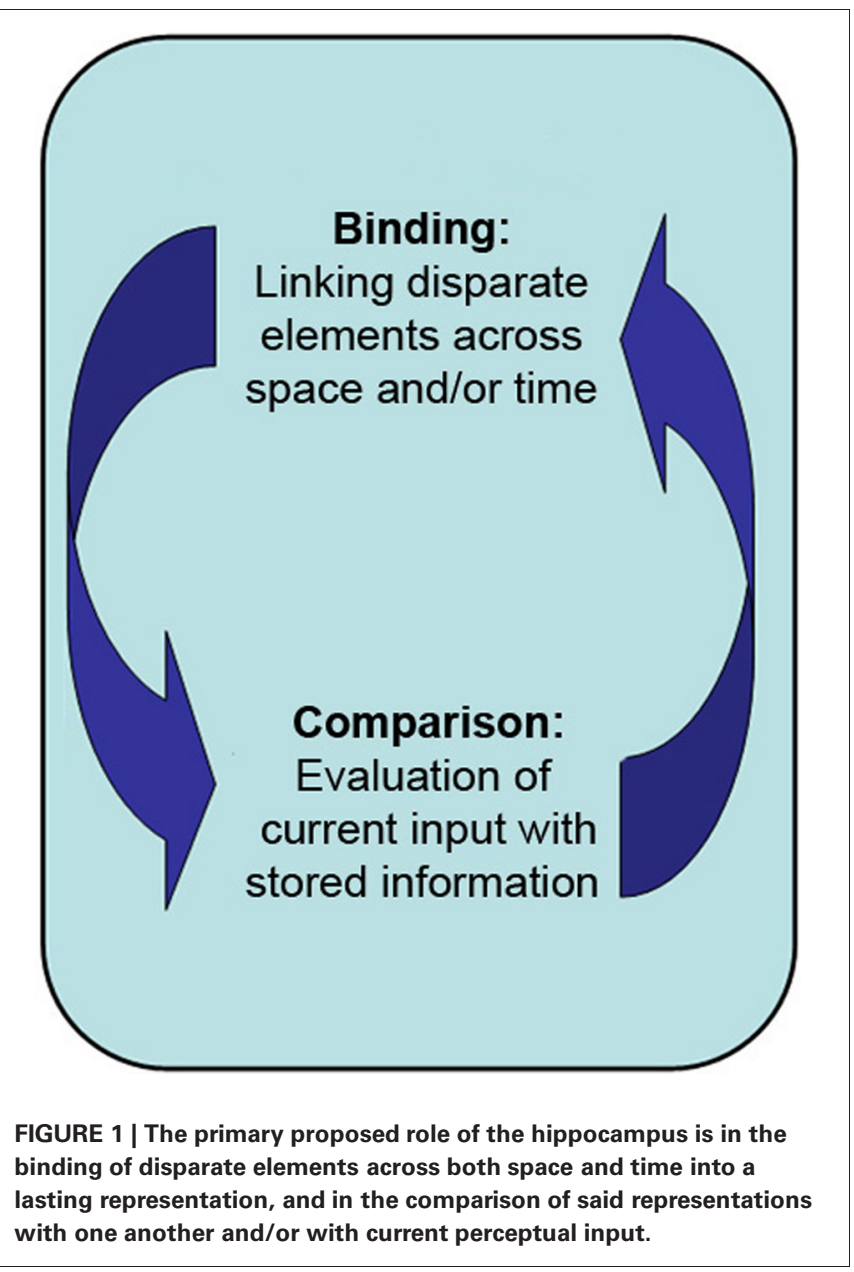

considerably longer period of time, and regardless of whether one has conscious appreciation for the use of those relational memory representations.

The above theoretical stance is supported by the functional organization of the hippocampus (Figure 2). Specifically, the hippocampus receives the output of processing from multiple, specialized, cortical regions (Cohen and Eichenbaum, 1993; Lavenex and Amaral, 2000; Cowell et al., 2010), which enables it to combine disparate inputs, including unimodal information from the visual and auditory streams, and polymodal inputs from the temporal and parietal lobes (Suzuki and Amaral, 1994a,b; Burwell and Amaral, 1998; Lavenex and Amaral, 2000). The anatomical structures within the hippocampus (e.g., CA1 and CA3 subfields) and between the hippocampus and entorhinal cortex enables the transmission of information necessary to perform binding and comparison (Hasselmo and Wyble, 1997; Vinogradova, 2001) and information is likely routed between these structures due to coordinated oscillatory activity (Colgin et al., 2009). Furthermore, emerging evidence has implicated the hippocampus as part of a network of brain regions that are involved in the evaluation of expectations through a comparison process (Lisman and Grace, 2005; Axmacher et al., 2010). In this way, the structure of the hippocampus is specialized for the integration and formation of representations that capture relational information within our environment, and such representations may be compared to current perceptual input and/or previously stored representations. Elsewhere, we and others have outlined the manner by which hippocampal binding contributes to long-term memory (Eichenbaum and Cohen, 2001; Ryan and Cohen, 2003; Moses and Ryan, 2006). Below, we provide a selective review of the literature that demonstrates how binding and comparison comprise the basic functions of the hippocampus which contribute to multiple stages of cognitive performance, including (but not limited to) recognition memory after shorter delays and perception, irrespective of whether cognitive performance requires conscious awareness regarding the use of those relational representations.

\section{THE ROLE OF THE HIPPOCAMPUS IN SHORT-DELAY RECOGNITION MEMORY

EVIDENCE FROM AMNESIA

Initial studies with amnesic patients suggested that the hippocampus plays a critical role in explicit long-term, but not short-term, recognition memory. Early studies of patient H.M. and other amnesics revealed intact memory for single items tested over short-delays (Penfield and Milner, 1958; Drachman and Arbit, 1966; Wickelgren, 1968; Baddeley and Warrington, 1970), but impaired memory once the typical immediate memory span was exceeded (around seven items; e.g., Drachman and Arbit, 1966). Such patterns of findings were observed on range of tasks, including digit span (Drachman and Arbit, 1966), recall of word triads (Warrington, 1981), and visual location memory for a single dot (Warrington and Baddeley, 1974), and were taken as evidence that the hippocampus plays a critical role in the creation of lasting memory representations (Squire, 1992; Cohen and Eichenbaum, 1993).

However, not all early studies regarding the nature of memory in amnesia reported findings of intact performance under 


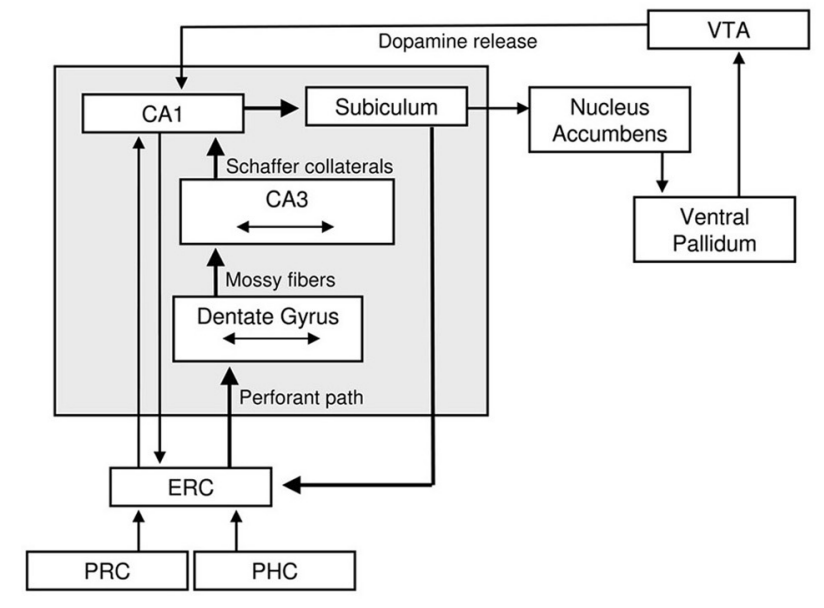

FIGURE 2 | Left: Neuroanatomical circuitry that supports binding and comparison. Arrows depict major connections between medial temporal lobe subregions that enable information flow. Brain regions that provide dopaminergic modulation are also depicted.

short-delay conditions. An early study by Warrington and Taylor (1973) showed that amnesic patients were impaired at face recognition even when tested immediately after the study phase (as well as following a $30 \mathrm{~s}$ delay). In addition, data from Prisko (1963) and Sidman et al. (1968) demonstrated that H.M.'s performance on delayed-matching of visual items was impaired after delays as short as 25-30 s. Similarly, Butters and colleagues (1973) reported that amnesics had trouble remembering nonsense shapes after a $20 \mathrm{~s}$ retention interval. Based on this pattern of findings, memory theorists at the time concluded that in contrast to verbal information, short-term memory for non-verbal materials seems to decay after about $20 \mathrm{~s}$ and that long-term memory must mediate performance at longer delays (O'Keefe and Nadel, 1978). Furthermore, Warrington and Taylor (1973) concluded that faces may be a special class of stimuli, for which long-term memory may be required for recognition even after immediate delays.

More recently, a number of studies have investigated the extent to which amnesics can remember information (typically visual) across retention intervals that were as brief as a few seconds (Hannula et al., 2006; Nichols et al., 2006; Olson et al., 2006a,b; Hartley et al., 2007; Piekema et al., 2007; Ezzyat and Olson, 2008; Finke et al., 2008; Shrager et al., 2008; Jeneson et al., 2010, 2011). Many of these studies required participants to form associations among distinct elements or items, including: faces and scenes (Hannula et al., 2006), colors and locations (Olson et al., 2006b; Finke et al., 2008), colors and numbers (Piekema et al., 2007), and objects and locations (Hannula et al., 2006). Other experiments required participants to maintain information regarding the spatial location of objects (Olson et al., 2006a,b; Jeneson et al., 2010) or the spatial topography of an outdoor scene (Hartley et al., 2007). Still other studies required participants to

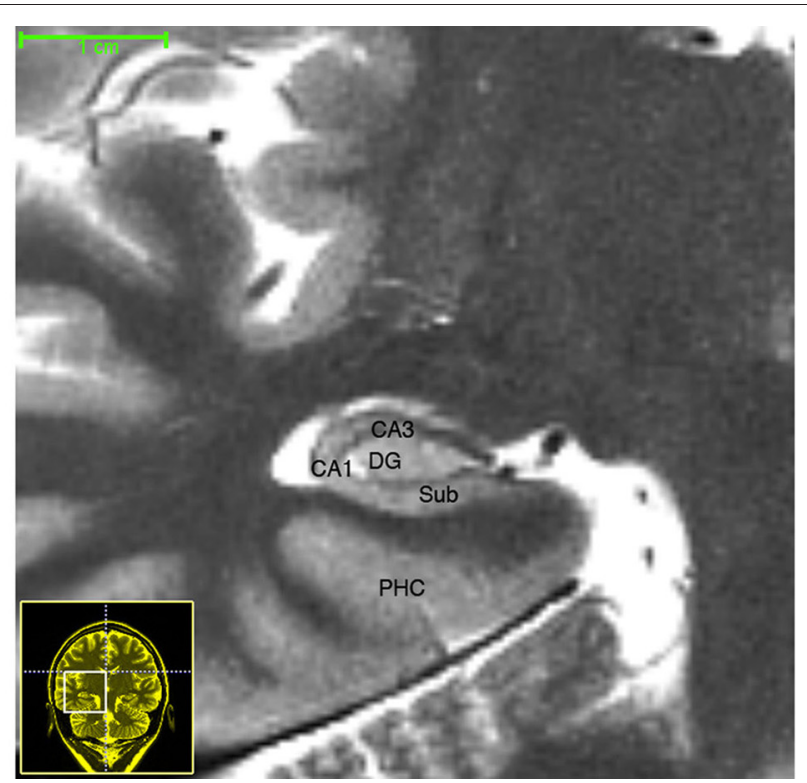

Right: High-resolution T-2 weighted image of the human MTL. Abbreviations: ERC, entorhinal cortex; PRC, perirhinal cortex; PHC, parahippocampal cortex; VTA, ventral tegmental area.

maintain information regarding a novel visual object (e.g., faces) for which multiple features must be integrated in order to perform a recognition memory test after a delay period of $1-8 \mathrm{~s}$ (Nichols et al., 2006; Olson et al., 2006b; Ezzyat and Olson, 2008; Rose et al., 2012). Despite the methodological differences, all studies pointed to a deficit in amnesic patients for remembering information over a short delay.

The findings reviewed above indicate that the hippocampus is engaged when multiple, distinct elements must be integrated or associated (Hannula et al., 2006; Olson et al., 2006b; Moses et al., 2007). This occurs readily for novel visual materials (e.g., Ezzyat and Olson, 2008; Rose et al., 2012) but is typically not required for familiar verbal materials, which can be maintained through subvocal rehearsal (a process which is supported by a network of extra-hippocampal cortical regions; Buchsbaum et al., 2005). Novel visual information may be difficult to maintain through verbal rehearsal if there are no meaningful phonological codes that can readily be used to accurately describe the material (Rose et al., 2012).

Thus, recognition tasks using short-delays that require memory for detailed visual information may rely on the hippocampus if the tasks require formation of associations among disparate elements or features across space (see also Lee et al., 2012). In addition to mediating the formation of relational memory representations that are based on disparate elements separated across space, the hippocampus is also critical for forming associations across time. For example, recognition of temporal sequences is impaired in amnesia (Konkel et al., 2008) and patients with hippocampal amnesia are impaired at learning associations when the two events are not contiguous in time, such as during trace conditioning paradigms (McGlinchey-Berroth et al., 1997; Clark and 
Squire, 1998). In contrast to the classical conditioning procedure, which involves the repeated, simultaneous, pairing of an unconditioned stimulus (e.g., air puff) with a conditioned stimulus (e.g., a tone and/or light), trace conditioning involves inserting a delay ( $\geq 500 \mathrm{~ms}$ ) between the conditioned and unconditioned stimulus. Thus, trace conditioning paradigms require the association of the unconditioned stimulus to the conditioned stimulus across time, which relies on the integrity of the hippocampus.

Taken together, these amnesia findings suggest that the hippocampus is responsible for the formation of relational memory representations, reflecting elements that are separated by space and time, and these representations can be subsequently accessed and compared after brief delays to guide recognition. However, inferences based on amnesic patients alone should be made with caution as some of the patients in the studies reviewed above likely presented with damage that extended beyond the hippocampus. As a result, findings from neuroimaging and non-human animal research have been important for providing converging evidence regarding the role of the hippocampus in supporting memory performance over short delays.

\section{EVIDENCE FROM NEUROIMAGING}

Results from the amnesia studies reviewed above provide evidence that the hippocampus contributes to performance on shortdelay tasks when disparate elements must be bound across space and/or time to support ongoing cognition and behavior. This account is also supported by studies of the healthy hippocampus in humans via neuroimaging techniques such as functional magnetic resonance imaging (fMRI). In addition, these neuroimaging studies provide critical information regarding the time at which the hippocampus is contributing to cognition.

fMRI studies from the past 10 years have implicated the hippocampus in delayed-recognition tasks that used short retention intervals (Ranganath and D'Esposito, 2001; Ranganath et al., 2005; Nichols et al., 2006; Piekema et al., 2006; Axmacher et al.,
2007; Hannula and Ranganath, 2009; Olsen et al., 2009; Toepper et al., 2010). Many of these imaging studies have used delayedmatch (DMS) or delayed-non-match-to-sample (DNMS) procedures in which a previously viewed item must be discriminated from a novel item (i.e., select the item that "matches" one that was previously viewed, or select the "non-matching" item). For example, Ranganath et al. (2005) reported hippocampal delay period activity when subjects performed a DMS task with a $7-13$ s delay period between study and test. Ranganath and colleagues also assessed recognition performance of the same items used in the DMS task after the scanning session and showed that delay activity in the hippocampus was greater for items subsequently recognized as compared to subsequently forgotten items. This is consistent with findings from the amnesic literature showing that the hippocampus is critical for the formation of long-term memory representations. Using a similar DMS task, Olsen and colleagues (2009) demonstrated that the hippocampal response was sustained across a $30 \mathrm{~s}$ delay period (see Figure 3), and therefore not simply a carryover response from the initial encoding episode. Critically, the delay period activity was predictive of concurrent short-delay memory performance.

All together, the sustained nature of the hippocampal response indicates that the hippocampus is playing an extended role beyond the encoding episode. This activity may reflect the continuous binding and comparison processes which are performed by the hippocampus, particularly in response to the task demands that require the online maintenance of relational representations. Furthermore, greater engagement of these processes leads to a more veridical/complete internal representation, and subsequently, more accurate memory performance on the task (Olsen et al., 2009). Thus, findings from neuroimaging studies, along with those from the amnesia literature, have provided converging evidence that the hippocampus is needed to form associations among disparate elements of a study episode in order to

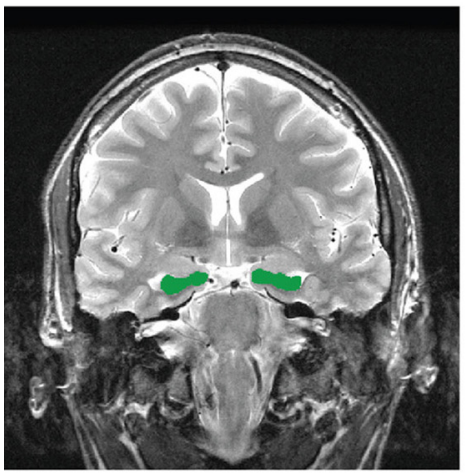

\section{Anterior hippocampus}

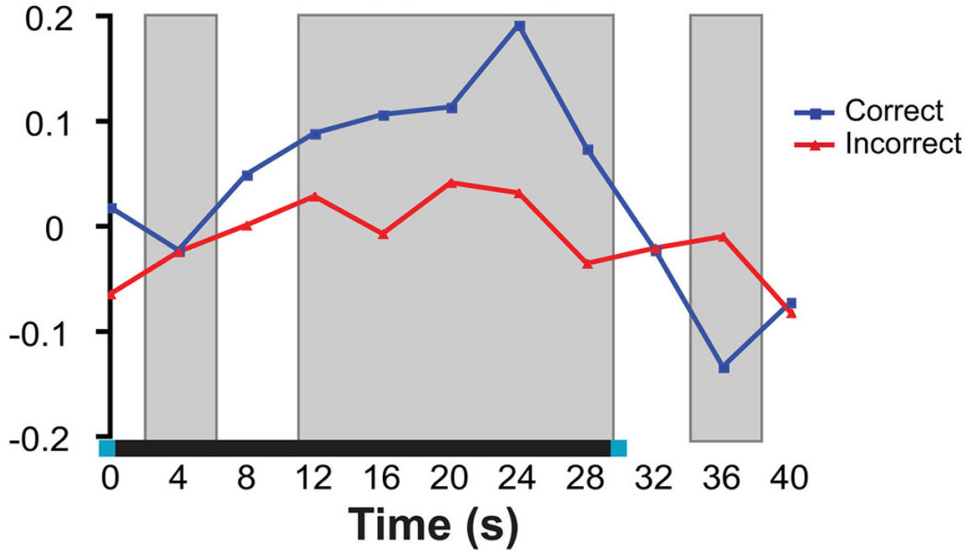

FIGURE 3 | Neuroimaging data from high-resolution fMRI in the anterior hippocampus during a short-delay recognition task. Left: Anatomical region of interest outlined in green; right: Neural response averaged across all voxels within the anterior hippocampus.
Delay-period activity was significantly greater for correct trials compared to incorrect trials. Right image was reproduced, with permission from, Olsen et al. (2009). Copyright @2009 Society for Neuroscience. 
successfully perform delayed-recognition following a brief retention interval.

\section{EVIDENCE FROM NON-HUMAN ANIMAL LESION AND RECORDING STUDIES}

Theories regarding the critical role of the hippocampus in cognition are significantly bolstered by investigations of non-human animals such as monkeys and rodents in which the specificity of recordings and lesions can be controlled and verified postmortem. Murray and Mishkin (1998) demonstrated that in monkeys with selective excitotoxic lesions to just the hippocampus, memory performance was not impaired on DNMS for single items across both short (10 s) and longer delays (up to $120 \mathrm{~s}$ ). By contrast, a rapid decline in DMS/DNMS performance was observed after damage to the medial temporal lobe (MTL) cortex in monkeys (Zola-Morgan et al., 1989; Meunier et al., 1993; Nemanic et al., 2004) and rats (Otto and Eichenbaum, 1992); indicating that the hippocampus and the MTL cortex play differential roles in memory for single items.

While selective hippocampal lesions in non-human animals typically do not cause impairments for short-delay recognition of single items, they result in consistent and profound deficits in short-term memory for relational representations such as spatial/location information. For example, hippocampal damage in rodents causes severe deficits on tasks in which animals must remember the arms of a recently visited maze (Olton et al., 1979) or a configuration of visual cues that specify the location of the platform in a modified DMS task (Prusky et al., 2004). In particular, Lee and Kesner (2003) demonstrated that lesions to specific subfields (CA3 and dentate gyrus) of dorsal hippocampus caused impairments on a delayed-matching to place task, which required rats to remember which arm of the maze previously contained a food reward, even when the delay between study and test was very brief (10s).

In the examples above, location memory required animals to form relational representations across both space and time, even when such representations were tested after a short-delay, due to the fact that animals could not visit multiple spatial locations simultaneously. Similarly, there is evidence from rodent lesion studies that the hippocampus plays a critical role in sequence learning (Fortin et al., 2002), which requires the formation of representations that contain both temporal and spatial associations. However, selective lesions to the hippocampus also cause impairments in tasks requiring animals to form a relational representation of information across time alone. As with hippocampal damage in humans, hippocampal lesions in nonhuman animals caused profound deficits in a trace conditioning paradigm (Moyer et al., 1990; Weiss et al., 1999; Bangasser et al., 2006), suggesting that binding the unconditioned stimulus to the conditioned stimulus across time relies on the integrity of the hippocampus.

Thus, lesion studies in animals have implicated the hippocampus to be critical for the short-term memory of spatial, temporal, and spatial-temporal representations. Interestingly, recording studies in animals have shown that cells in the hippocampus may play a role in "bridging the gap" and associating spatial-temporal information across brief delays (Deadwyler and Hampson, 2004).
MacDonald and colleagues (2011) recently found that when rodents were performing a task that required the association between a sequentially presented object and odor, cells in the hippocampus fired at a particular time during the delay interval between the object and odor presentations. These so-called "time cells" may play an important role in maintaining and binding disparate pieces of information (e.g., the object and odor representations) across time. Taken together with the neuroimaging findings reviewed above, delay-period activity in the hippocampus seems to play an important role in linking spatially and/or temporally discontiguous items or events.

In summary, findings from amnesia, neuroimaging, and nonhuman animal lesion studies, have provided evidence for involvement of the hippocampus in short-delay recognition memory. These studies show that while the hippocampus is not always critical for successful short-delay recognition of single items, it is recruited when information regarding multiple disparate elements must be associated and maintained across time and/or rapidly encoded and subsequently compared to the test stimulus. Moreover, the hippocampus is more likely to be required to support performance over short-delays when the to-be-remembered associations are not readily prone to verbal rehearsal (such as detailed visual and/or spatial information), that would otherwise maintain the information in an active state.

\section{THE ROLE OF THE HIPPOCAMPUS IN PERCEPTION}

The findings reviewed above have caused memory researchers to question the long-standing view of the critical role of the hippocampus in long-term recognition memory exclusively. Specifically, there appears to be a role for the hippocampus in short-term, as well as long-term, memory. Moreover, emerging evidence suggests that the hippocampus is also involved in tasks that do not have an overt memory component; that is, the hippocampus may contribute to processing in the present moment, and not just over a delay. Such findings challenge the notion that the hippocampus is strictly involved in memory processing and instead, extend the reach of the hippocampus' role into other cognitive domains, such as perception.

\section{EVIDENCE FROM AMNESIA AND NEUROIMAGING}

Neuropsychological and neuroimaging studies have indicated a role for the hippocampus in tasks that are typically thought to require purely perceptual processing - that is, tasks that require little to no retention of information across time. For instance, Lee and colleagues $(2005 \mathrm{a}, \mathrm{b})$ demonstrated that amnesic patients were impaired when they were asked to make visual discriminations among scenes. Complementary fMRI evidence from this research group revealed that the posterior hippocampus was more active when participants performed oddity discrimination judgments on scenes versus a size judgment task on simple shapes (Lee et al., 2008). Using magnetoencephalography (MEG), Riggs et al. (2009) outlined the temporal dynamics underlying hippocampal activity. During a scene recognition task, hippocampal responses were observed to both novel and previously studied scenes very early during processing, within the first $150 \mathrm{~ms}$ following scene presentation (Figure 4). These hippocampal responses occurred within the time window typically associated 


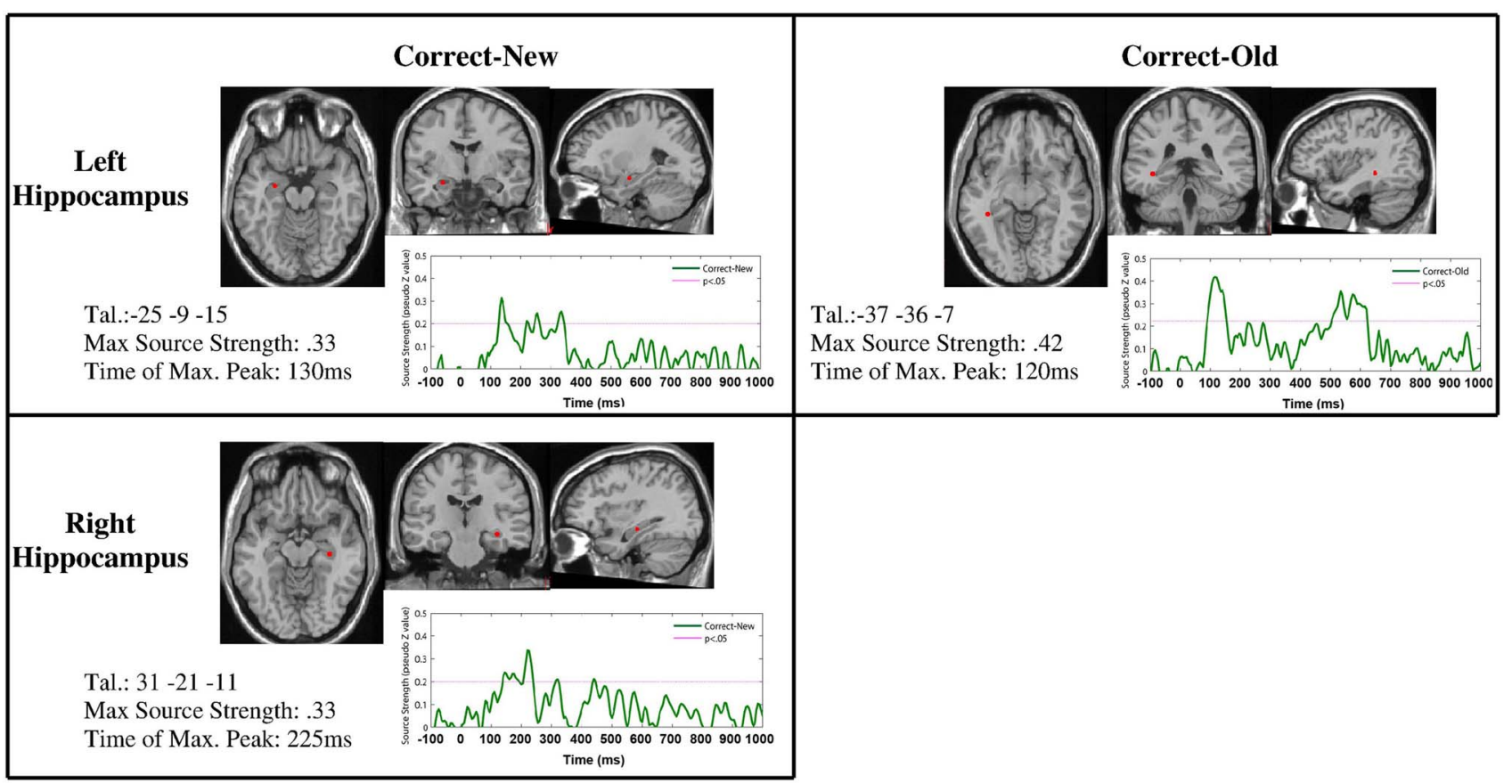

FIGURE 4 | Early ( 150 ms post stimulus onset) hippocampal response detected with MEG. Reprinted from Riggs et al. (2009), Copyright (2009), with permission from Elsevier.

with perceptual processing (Thorpe et al., 1996; VanRullen and Thorpe, 2001) and well before any recognition memory judgment was required.

Findings regarding the recruitment of the hippocampus in tasks that are traditionally considered "perceptual" in nature, and hippocampal responses that occur during a time at which perception is typically thought to occur, have been taken as evidence that the hippocampus is critically involved in perceptual processing [reviewed by Graham and colleagues (2010) and by Lee and colleagues (2012)]. One possible mechanism by which the hippocampus contributes to perception is through the formation and comparison of relational memory representations. For example, the oddity-judgment task employed by Lee and colleagues (2005a) requires careful scrutiny of the visual stimuli in order to select the "odd" stimulus. This task required participants to maintain a representation of one or more of the scenes until it could be compared to the one of the other presented scenes (see Figure 5 for an example of the type of scene stimuli used by Lee and colleagues). Thus, the task likely required participants to first build up a representation of one scene, hold that representation online (or at least maintain some of the disparate elements regarding the scene online) and compare it to other scenes until the odd-one-out is determined. A similar demonstration of impaired performance by amnesic patients on a perceptual matching task indicated that, in the absence of a functioning hippocampus, sampled visual information degrades more quickly, ultimately making comparison difficult and thereby prompting the continual re-sampling of the stimuli by the eyes (Warren et al., 2011).

We suggest that visual discrimination tasks, such as those employed by Lee and colleagues and Warren and colleagues, likely recruit the same binding and comparison processes that are invoked in more traditional memory tasks, such as the recognition task used by Riggs and colleagues noted above. The outputs of the binding and comparison processes performed by the hippocampus can be used guide or bias attention in a way that helps to resolve perceptual ambiguity, or otherwise facilitate the formation of a coherent percept. For example, behavioral and eye-movement studies have indicated that surrounding scene information can facilitate identification of individual objects nested within the scene (Hollingworth, 2007), or direct the eyes to the areas of an image that are most suitable for task goals (Yarbus, 1967). Thus, memory representations mediated by the hippocampus regarding associations among objects, places, or temporal sequences can be used in an online manner to support identification and or interpretation of externally presented information.

Further evidence of the online use of associated information in memory during the time at which perception is thought to occur comes from Ryan and colleagues (2008). In this study, activation within the visual cortex was larger for auditorily presented famous names compared to nonfamous names-suggesting that the auditory perception of a word can elicit retrieval of the visual information (i.e., face) associated with that name. Similarly, activation within the auditory cortex was greater for visually presented famous faces compared to nonfamous faces. This crossmodal recruitment occurred very early during processing, within the first $200 \mathrm{~ms}$, even though retrieval of such associated information was not required for to perform the task at hand. This suggests that memories for associated information were retrieved in an obligatory manner. The hippocampus was likely not critical 

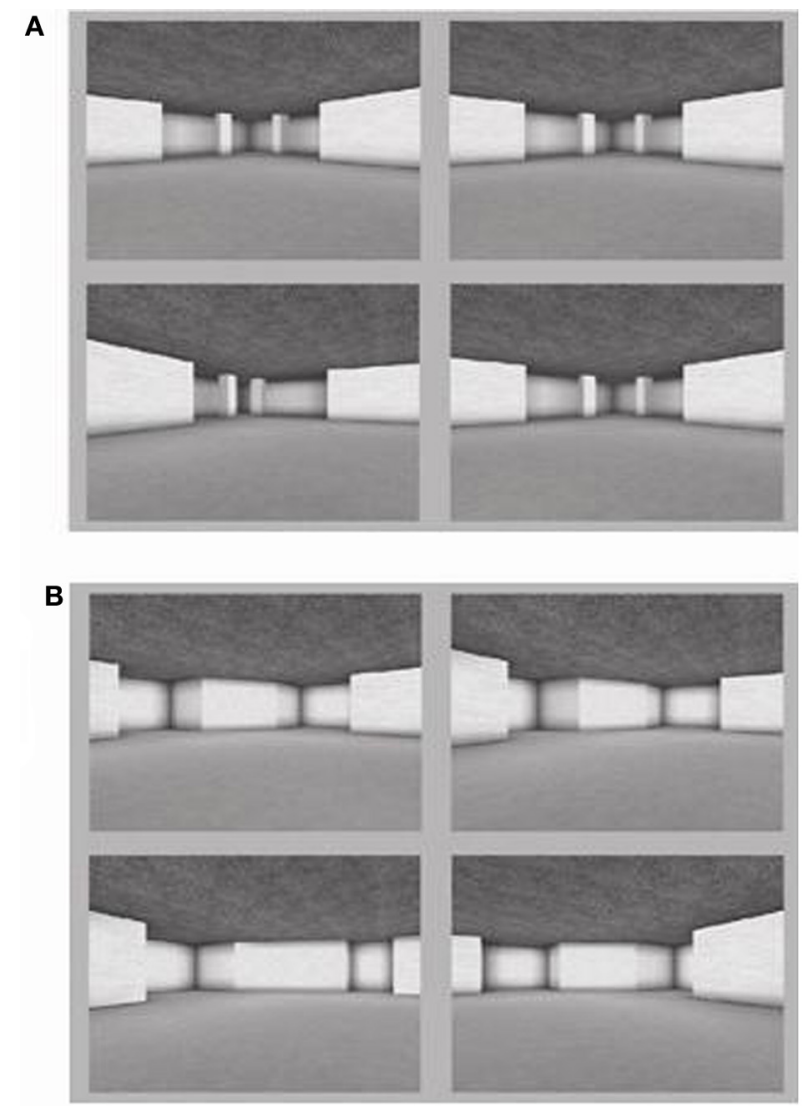

FIGURE 5 | Scene stimuli used by Lee and colleagues (2005a) to assess whether amnesic patients were impaired at visual discrimination of scenes. Adapted with permission from Lee et al. (2005). Copyright @2005 Wiley-Liss Inc.

for the retrieval of the cross-modal visual-face and auditory-name information in this task, given that the face-name associations were learned years prior to the experimental test session, and were presumably semantic in nature (Squire and Alvarez, 1995; Nadel and Moscovitch, 1997). However, considerable evidence would suggest that the hippocampus would have been critical for establishing the face-name association within memory during the time of initial learning (Sperling et al., 2001; Zeineh et al., 2003). The hippocampus is the recipient of afferent connections from visual/auditory cortices (Burwell and Amaral, 1998) and efferent connections from the hippocampus to these same sensory areas have also been observed (Agster and Burwell, 2009); thus, the hippocampus is ideally situated to bind information from these distinct sensory areas. This linkage between a famous person's face and his/her name results in the cross-modal activation observed in sensory areas when elements of this previously bound representation are cued. Taken together with the MEG findings reported by Riggs et al. (2009), the rapid retrieval of associated knowledge (i.e., the name of the famous face) may even augment the perceptual experience afforded by the visual input.

In summary, the findings reviewed above suggest that the hippocampus may be involved during early perceptual processing of old and new information, by virtue of continuous, ongoing binding and comparison processes. Furthermore, relational representations that were previously established by virtue of hippocampal binding and comparison can be retrieved obligatorily, and, in turn, influence online processing and subsequent behavior. These results, taken together with the aforementioned work pointing to a role of the hippocampus in short-term memory performance, show that the hippocampus is not simply involved in long-term recognition memory. Rather, the primary function of the hippocampus appears to be more basic than previously assumed and a comprehensive theory of hippocampal function must explain the role it plays in short-term recognition memory and perception.

\section{RECONCILING THE FINDINGS: RELATIONAL BINDING AND COMPARISON}

The full range of evidence to date clearly demonstrates that the reach of the hippocampus extends far beyond its traditionally ascribed role in recognition memory. Our group and others have argued that the hippocampus plays a critical role in the formation of relational memory representations that can be used in service of any task at hand, regardless of whether the task was designed to test mostly memory or mostly perception (Ryan and Cohen, 2003; Konkel and Cohen, 2009; Graham et al., 2010). That is, the hippocampus mediates the binding of multiple, disparate elements across space and time into a lasting representation (Cohen and Eichenbaum, 1993; Cohen et al., 1997; Ryan and Cohen, 2003; Moses and Ryan, 2006; Konkel et al., 2008). These relational representations may be maintained in an active state or be subsequently reactivated in service of online processing, i.e., the comparison of externally presented information with internally stored memory representations (Ryan and Cohen, 2004b). The hippocampus, via these aforementioned processes, contributes to a multitude of cognitive processes, including (but not limited to) perception, short-delay maintenance and retrieval, and long-term recognition.

The findings reported in this review can be readily interpreted in the context of a critical role of the hippocampus for relational binding and comparison. Specifically, impairments among amnesic patients on short-delay recognition memory tasks and perceptual processing tasks may reflect the inability to form relational memory representations and/or an inability to continuously compare externally presented information with internally maintained/stored associated information. In the section below, we will elaborate on the tenets of relational binding and comparison and explain in further detail how this idea accounts for the data reviewed above.

\section{THE TENETS OF RELATIONAL BINDING AND COMPARISON}

The formation of relational representations relies on two subprocesses: (1) binding and (2) comparison (Figure 1). Binding involves the association or linking of disparate elements, each of which are stored separately and uniquely accessible within cortex, resulting in a stored representation that is flexible in nature (for further discussion, see Eichenbaum and Cohen, 2001; Moses and Ryan, 2006; Mayes et al., 2007). Comparison occurs when recently processed perceptual information is evaluated with 
respect to associated or otherwise relevant, information that is maintained in memory (Vinogradova, 2001; Ryan and Cohen, 2004a,b; Kumaran and Maguire, 2007). Binding and comparison are two processes that occur continuously; moreover, they are intertwined such that one can affect the other, possibly in a cyclical manner akin to a feedback loop (Jensen and Lisman, 1996; Meeter et al., 2004). In other words, as soon as perceptual input reaches the hippocampus, the binding process begins and the output of that binding process is compared to the relevant representations stored in memory. In this way, stored representations in memory may influence online processing, by signaling which information needs to be either strengthened and/or modified in its content. Critically, the ongoing binding/comparison feedback process repeats and its resulting outputs guide online processing and subsequent behavior.

Binding and comparison can occur at any given time, such as during the initial encoding episode and during memory retrieval; however, one process may be recruited to a greater or lesser extent depending on the experience with a given stimulus, and/or the nature of the task demands. The relative novelty of the stimulus may differentially recruit the binding and comparison processes. For example, completely novel stimuli may bias the hippocampus to perform binding rather than comparison. Conversely, stimuli that have been previously encountered frequently may stimulate comparison and downplay the role of binding. Furthermore, comparison might be especially dominant under situations in which previously linked associations are "violated" (Kumaran and Maguire, 2006, 2007). This proposal is supported by reports of increased hippocampal activity when information that had previously been associated with a specific temporal sequence is now re-presented with a new temporal sequence (ABCD is now presented as ABDC; Kumaran and Maguire, 2006). Of particular interest is the fact that conditions of a "mismatched" temporal sequence elicited increased hippocampal activity compared to a completely novel sequence of the studied items (CADB or BDAC)—suggesting that the comparison process performed by the hippocampus was not simply a global match process, as is thought to occur within the MTL cortex (Norman and O'Reilly, 2003; Kumaran and Maguire, 2007).

\section{THE HIPPOCAMPUS SUPPORTS COMPARISON}

While the role of the hippocampus in relational binding can be clearly gleaned from previous studies of short-term recognition memory using DMS and DNMS tasks (see Section "The Role of the Hippocampus in Short-delay Recognition Memory"), the role of the hippocampus in comparison merits further discussion. Through comparison, the hippocampus detects similarities/differences between the current perceptual input and stored memory representations, in the service of guiding subsequent cognitive processing and behavior (Vinogradova, 2001). While there is still uncertainty regarding which hippocampal subregions are involved in this comparison process (Hasselmo, 2005; Lee et al., 2005), it has been proposed that the hippocampus receives information about the current stimulus via afferent projections into the CA1 subfield via entorhinal cortex (the major input structure of the hippocampus). CA1 also receives information regarding stored representations that are similar to the current stimulus from the neuroanatomically distinct CA3 subfield (Jensen and Lisman, 1996). According to comparator models, CA1 compares the representations from CA3 and entorhinal cortex and outputs a novelty signal when these representations do not match (Hasselmo and Wyble, 1997; Vinogradova, 2001).

As mentioned previously, the patterns of anatomical connectivity both within the hippocampus and between the hippocampus and the neocortex, provides the structural architecture necessary to complete binding and comparison (see Figure 2). Furthermore, different patterns of oscillatory brain activity observed within the hippocampus likely play an important role in routing of information in the brain, which drives the binding and comparison mechanisms. For example, phase synchronization between two different regions of the brain which both synapse onto the same target cell in the hippocampus could enable binding (see Fell and Axmacher, 2011, for a review). Indeed, phase synchronization both within the hippocampus (Rutishauser et al., 2010) and between the hippocampus and the rhinal cortex (Fell et al., 2001, 2003) has been associated with successful memory formation in humans. Similarly, it has recently been demonstrated that the frequency of gamma oscillations may affect the flow of information in the hippocampus (Colgin et al., 2009). In this study, fast gamma oscillations in CA1 were synchronized with the entorhinal cortex and slow gamma oscillations in CA3 were synchronized with the entorhinal cortex. Future studies might be able to isolate the contributions of binding and comparison by examining how phase coherence within the MTL relates to different behavioral profiles.

Recent evidence from high-resolution fMRI in humans has indicated that CA1 plays a pivotal role in the comparison of previously associated information (Chen et al., 2011; Duncan et al., 2012). Intracranial recordings in humans have further strengthened the role of the hippocampus in comparison by demonstrating a change in neural activity which likely reflected the violation of expectation based on previous input (Axmacher et al., 2010). These same neural signals further predicted successful memory formation, indicating a role for the hippocampus in both comparison and in the formation of a lasting memory trace (i.e., binding). This study provided critical experimental evidence that comparison processes performed by the hippocampus can subsequently trigger new learning when the current stimulus is sufficiently different from stored memory representations (Lisman and Grace, 2005) or recently presented information (Kumaran and Maguire, 2007). This comparison mechanism, which relies on the reinstatement of previously formed associations, allows for reorganization (re-binding) of the relationships between stored memory representations in cortex. While some initial binding may need to occur within cortical areas before comparison is initiated by the hippocampus, it remains to be determined whether either binding or comparison can occur in isolation from the other (see Section "Avenues for Future Research").

\section{THE OBLIGATORY (AND UNCONSCIOUS) BINDING AND COMPARISON OF RELATIONAL REPRESENTATIONS}

The relational memory processes performed by the hippocampus may occur (1) obligatorily and (2) with or without conscious awareness of the retrieved information. Evidence in support of the 
obligatory role of the hippocampus in relational binding includes studies showing that the hippocampus is involved rapidly in the processing stream and without reference to the particular task demands. For example, as mentioned above, MEG studies report peak responses within the hippocampus very early $(<150 \mathrm{~ms}$ after stimulus onset; e.g., Riggs et al., 2009). Further, such responses were found to occur under different task conditions (e.g., in response to both new and old stimuli), suggesting that memory for prior experiences influences online processing in an obligatory manner ${ }^{1}$. Intracranial recordings of hippocampal neurons in nonhuman animals also exhibit a short latency post-stimulus onset (152 ms for both familiar and novel stimuli; Yanike et al., 2004). In humans, neuronal recording studies have reported slightly longer latencies (300-400 ms post stimulus onset), with firing latencies occurring significantly later in the hippocampus compared to parahippocampal cortex (Quiroga et al., 2005; Mormann et al., 2008). In addition to these neuroimaging and neuronal recording results, hippocampal-based eye-movement memory effects have also provided evidence for the early involvement of the hippocampus in online processing (Ryan et al., 2000; Ryan and Cohen, 2004a,b; Hannula et al., 2007, 2010).

A variety of experimental findings have also revealed that the hippocampus supports relational binding and comparison with or without conscious awareness for the memory representations that are formed, retrieved and/or compared (for a more detailed review, the reader is directed to Hannula and Greene, 2012). For example, Ryan et al. (2000) showed that neurologically intact controls looked disproportionately at regions of scenes that had undergone a change in spatial relationships, even when they were unaware of the nature of the change that had occurred. Critically, this relational eye-movement effect was not observed in amnesic patients. As reviewed by Hannula and colleagues (2010), similar relational eye-movement behavior patterns that occur outside of conscious awareness have been reported by other groups (Hayhoe et al., 1998; Hollingworth et al., 2001, 2008; Hollingworth and Henderson, 2002; Henderson and Hollingworth, 2003; Beck et al., 2007; Hollingworth, 2009). Furthermore, while controversial (Manns and Squire, 2001; Smith and Squire, 2005), there is considerable evidence that the hippocampus plays a critical role in other tasks that require relational processing such contextual cueing and analogical transfer, which requires learning the relations among the presented stimuli, irrespective of conscious awareness for the stored relations (Chun and Phelps, 1999; Greene et al., 2001, 2006; Reder et al., 2009).

Taken together, such findings reveal that memory representations for relational information are formed obligatorily and can be retrieved even in the absence of conscious awareness for the prior learning episode. Moreover, these representations are not only retrieved, they are also compared to currently presented information, such that changes may be detected-which may ultimately influence subsequent behavior, including further

\footnotetext{
${ }^{1}$ A similar proposal was put forward by Nadel and Moscovitch (1997)— that the hippocampus obligatorily encodes information as soon as it is apprehended and available to consciousness. By contrast, we argue here that the hippocampus performs binding on information of which the individual is not necessarily consciously aware (see Henke, 2010 for a similar proposal).
}

eye-movement sampling (e.g., Ryan et al., 2000; Ryan and Cohen, 2004b; Hannula et al., 2007). This cycle of relational binding and comparison depends critically on the integrity of the hippocampus such that in the absence of a functioning hippocampus, the cycle and the processes contained therein are disrupted.

\section{IS THE HIPPOCAMPUS CRITICAL FOR ALL TYPES OF BINDING AND COMPARISON?}

Evidence from amnesia and non-human animal lesion studies suggests that brain regions outside of the hippocampus can also perform binding and comparison; however binding and comparison within distinct neural regions differ with respect to the type of representation that is being bound/compared. For example, selective hippocampal lesions do not typically disrupt performance on tasks in which the processing of, or memory for, a single object is required (Althoff et al., 1993; Althoff, 1998; Murray and Mishkin, 1998). By contrast, memory performance on tasks that require the formation of relationships among distinct objects or between objects and surrounding background information is markedly impaired by hippocampal damage (Ryan et al., 2000; Hannula et al., 2007). This evidence points to a role for the hippocampus and MTL cortex in between-object and within-object binding, respectively (Murray and Bussey, 1999; Cowell et al., 2006; Staresina and Davachi, 2006, 2008, 2010; Barense et al., 2007).

Additionally, just as there are varying levels of binding that occur along the neural hierarchy (moving from MTL cortex to hippocampus), there may be different levels of comparison that occur along the same neural hierarchy. We suggest that comparison processes within the hippocampus and MTL cortex operate on fundamentally distinct representations to which these regions have access (Norman and O'Reilly, 2003; Kumaran and Maguire, 2007). Comparison within MTL cortex would operate on feature and object information, which can be contrasted with comparison mediated by the hippocampus that operates on relational representations.

As reviewed above, certain task manipulations can change the nature of the processing required to compare individual objects, such that instead of comparing the object as a whole, individual features of the object might be processed in isolation as well as with respect to one another (Moses and Ryan, 2006). For instance, when a task requires the discrimination between previously viewed objects and highly perceptually similar lures, as in Ezzyat and Olson (2008) and in Rose et al. (2012), the features that are contained within the target items and the lures are treated as distinct entities, and therefore as their own "objects." The relations among these "objects" for target versus lure items are likely then bound and compared against each other, thus requiring the hippocampus. Thus, both the type of information being processed (object vs. relational) as well as the nature of the representations required by the task play a role in determining whether the hippocampus is critical for task performance.

When delays between study and test presentation are short, prefrontal areas may also contribute to the online comparison process performed by the hippocampus or even perform a separate comparison processes independent of the hippocampus 
(Kesner, 1989; Winocur and Moscovitch, 1990; Ryan and Cohen, 2004a,b). This is evidenced by the fact that hippocampal amnesics can accurately process relational information, and show, similar to neurologically-intact controls, increases in eye-movement behavior to regions of a scene where a relational change has occurred (Ryan and Cohen, 2004a,b). However, as processing demands increase, such as when the number of relations to be maintained is large and/or conceptually or perceptually similar to those maintained on previous trials, the hippocampus becomes necessary for task performance, even after short delays (Hannula et al., 2006). Thus, while binding and comparison computations may be mediated by multiple neural regions, the hippocampus is critical for these computations when relational information must be maintained over longer delays and/or when information has a high degree of conceptual/perceptual overlap, regardless of whether the information must be maintained over a delay or merely discriminated in the present moment.

\section{AVENUES FOR FUTURE RESEARCH}

In this review, we have proposed that binding and comparison are two basic and fundamental processes performed by the hippocampus. However, future research is needed to further specify the exact neural mechanisms that enable binding and comparison. Future studies could help define which particular subregions of the hippocampus perform these functions and the manner by which they communicate. Emerging evidence indicates that phase synchronization between different areas within the MTL and/or between the hippocampus and neocortex may enable the linking and routing of information necessary to perform binding and comparison. Recording studies in animals and humans can provide further evidence that coherence between distinct sets of neural regions correlates with successful binding versus comparison. Furthermore, lesion/inactivation studies could be used to disentangle the selective contributions of binding and comparison to task performance, and more generally, shed light on the extent to which binding or comparison can occur independently from the other.

Another area of future research could focus on whether the role of the hippocampus in comparison is time-limited-in other words, does hippocampally-mediated comparison only occur for newly formed memory representations? While some theories of hippocampal function suggest that the hippocampus is not necessary for the retrieval of remote memories (Squire and Alvarez,

\section{REFERENCES}

Agster, K. L., and Burwell, R. D. (2009). Cortical efferents of the perirhinal, postrhinal, and entorhinal cortices of the rat. Hippocampus 19, 1159-1186.

Althoff, R. R. (1998). EyeMovement-Based Memory Assessment: The Use of Eye Movement Monitoring as an Indirect Measure of Memory. Unpublished doctoral dissertation, Urbana, University of Illinois at Urbana-Champaign.
Althoff, R. R., Maciukenas, M., and Cohen, N. J. (1993). Indirect assessment of memory using eye movement monitoring. Abstr. Soc. Neurosci. 19, 439.

Axmacher, N., Cohen, M. X., Fell, J., Haupt, S., Dumpelmann, M., Elger, C. E., Schlaepfer, T. E., Lenartz, D., Sturm, V., and Ranganath, C. (2010). Intracranial EEG correlates of expectancy and memory formation in the human hippocampus and nucleus accumbens. Neuron 65, 541-549.

1995), other theories posit that the hippocampus is always needed for retrieval of episodic memories, regardless of the age of the memory (Nadel and Moscovitch, 1997). Alternatively, comparison may critically require the hippocampus even if the retrieval of the relevant memory representation (either episodic or semantic in nature) is no longer hippocampal-dependent. If this framing of hippocampal function is accurate, it may explain why patient $\mathrm{KC}$, who has significant bilateral hippocampal damage, is impaired at recognizing specific spatial landmarks (e.g., houses from the patient's neighborhood) despite having relatively preserved overall knowledge of these same spatial environments (Rosenbaum et al., 2000).

\section{CONCLUSION}

It is clear that the reach of the hippocampus extends well beyond explicit long-term recognition memory. A wealth of evidence suggests that the hippocampus can play a role in a variety of cognitive tasks including (but not limited to): short-term recognition memory, perception, and long-term recognition memory with and without conscious awareness; and thus a more comprehensive model of hippocampal function is needed to accommodate the full range of data. To this aim, we have argued that the critical role of the hippocampus is the formation of lasting, flexible, relational representations, which require the two sub-processes of binding and comparison. Relational binding involves the association of disparate elements, which can be separated by space and/or time, and comparison involves the evaluation of externally presented information with stored/associated memory representations. These processes occur continuously and in an obligatory manner, irrespective of conscious awareness for the binding or comparison process.

From this perspective, it is perhaps not surprising that the hippocampus contributes to a variety of cognitive processes. While this review focused on the role of the hippocampus in recognition memory after short-delays and during perception, the functional reach of the hippocampus extends into a multitude of cognitive domains not reviewed here such as imagination, future thinking, problem solving, and spatial navigation. By virtue of binding and comparison, the hippocampus allows for prior experiences to continually and efficiently influence online processing and behavior without the need for exhaustive top-down control. In this way, the contributions of the healthy hippocampus lead to a remarkably efficient system, facilitating cognition at every stage of processing.

Axmacher, N., Mormann, F., Fernandez, G., Cohen, M. X., Elger, C. E., and Fell, J. (2007). Sustained neural activity patterns during working memory in the human medial temporal lobe. $J$. Neurosci. 27, 7807-7816.

Baddeley, A. D., and Warrington, E. K. (1970). Amnesia and the distinction between long- and short-term memory. J. Verbal Learn. Verbal Behav. 9, 176-189.

Bangasser, D. A., Waxler, D. E., Santollo, J., and Shors, T. J.
(2006). Trace conditioning and the hippocampus: the importance of contiguity. J. Neurosci. 26, 8702-8706.

Barense, M. D., Gaffan, D., and Graham, K. S. (2007). The human medial temporal lobe processes online representations of complex objects. Neuropsychologia 45, 2963-2974.

Beck, M. R., Peterson, M. S., and Angelone, B. L. (2007). The roles of encoding, retrieval, and awareness in change 
detection. Mem. Cognit. 35, 610-620.

Buchsbaum, B. R., Olsen, R. K., Koch, P., and Berman, K. F. (2005). Human dorsal and ventral auditory streams subserve rehearsalbased and echoic processes during verbal working memory. Neuron 48 , 687-697.

Burwell, R. D., and Amaral, D. G. (1998). Cortical afferents of the perirhinal, postrhinal, and entorhinal cortices of the rat. J. Comp. Neurol. 398, 179-205.

Butters, N., Lewis, R., Cermak, L. S., and Goodglass, H. (1973). Material specific memory deficits in alcoholic Korsakoff patients. Neuropsychologia 11, 291-299.

Cave, C. B., and Squire, L. R. (1992). Intact verbal and nonverbal shortterm memory following damage to the human hippocampus. Hippocampus 2, 151-163.

Chen, J., Olsen, R. K., Preston, A. R., Glover, G. H., and Wagner, A. D. (2011). Associative retrieval processes in the human medial temporal lobe: hippocampal retrieval success and CA1 mismatch detection. Learn. Mem. 18, 523-528.

Chun, M. M., and Phelps, E. A. (1999). Memory deficits for implicit contextual information in amnesic subjects with hippocampal damage. Nat. Neurosci. 2, 844-847.

Clark, R. E., and Squire, L. R. (1998). Classical conditioning and brain systems: the role of awareness. Science 280, 77-81.

Cohen, N. J., and Eichenbaum, H. (1993). Memory, Amnesia and the Hippocampal System. Cambridge, MA: MIT Press.

Cohen, N. J., Poldrack, R. A., and Eichenbaum, H. (1997). Memory for items and memory for relations in the procedural/declarative memory framework. Memory 5, 131-178.

Cohen, N. J., Ryan, J., Hunt, C., Romine, L., Wszalek, T., and Nash, C. (1999). Hippocampal system and declarative (relational) memory: summarizing the data from functional neuroimaging studies. Hippocampus 9, 83-98.

Colgin, L. L., Denninger, T., Fyhn, M., Hafting, T., Bonnevie, T., Jensen, O., Moser, M. B., and Moser, E. I. (2009). Frequency of gamma oscillations routes flow of information in the hippocampus. Nature 462, 353-357.

Corkin, S. (1968). Acquisition of motor skill after bilateral medial temporal lobe excision. Neuropsychologia 6, 255-265.

Cowell, R. A., Bussey, T. J., and Saksida, L. M. (2006). Why does brain damage impair memory? A connectionist model of object recognition memory in perirhinal cortex. J. Neurosci. 26, 12186-12197.

Cowell, R. A., Bussey, T. J., and Saksida, L. M. (2010). Components of recognition memory: dissociable cognitive processes or just differences in representational complexity? Hippocampus 20, 1245-1262.

Deadwyler, S. A., and Hampson, R. E. (2004). Differential but complementary mnemonic functions of the hippocampus and subiculum. Neuron 42, 465-476.

Drachman, D. A., and Arbit, J. (1966). Memory and the hippocampal complex. II. Is memory a multiple process? Arch. Neurol. 15, 52-61.

Duncan, K., Ketz, N., Inati, S. J., and Davachi, L. (2012). Evidence for area CA1 as a match/mismatch detector: a high-resolution fMRI study of the human hippocampus. Hippocampus 22, 389-398.

Eichenbaum, H., and Cohen, N. J. (2001). From Conditioning to Conscious Recollection: Memory Systems of the Brain. New York, NY: Oxford University Press.

Ezzyat, Y., and Olson, I. R. (2008). The medial temporal lobe and visual working memory: comparisons across tasks, delays, and visual similarity. Cogn. Affect. Behav. Neurosci. 8, 32-40.

Fell, J., and Axmacher, N. (2011). The role of phase synchronization in memory processes. Nat. Rev. Neurosci. 12, 105-118.

Fell, J., Klaver, P., Elfadil, H., Schaller, C., Elger, C. E., and Fernandez, G. (2003). Rhinal-hippocampal theta coherence during declarative memory formation: interaction with gamma synchronization? Eur. J. Neurosci. 17, 1082-1088.

Fell, J., Klaver, P., Lehnertz, K., Grunwald, T., Schaller, C., Elger, C. E., and Fernandez, G. (2001). Human memory formation is accompanied by rhinalhippocampal coupling and decoupling. Nat. Neurosci. 4, 1259-1264.

Finke, C., Braun, M., Ostendorf, F., Lehmann, T. N., Hoffmann, K. T., Kopp, U., and Ploner, C. J. (2008). The human hippocampal formation mediates short-term memory of colour-location associations. Neuropsychologia 46, 614-623.

Fortin, N. J., Agster, K. L., and Eichenbaum, H. B. (2002). Critical role of the hippocampus in memory for sequences of events. Nat. Neurosci. 5, 458-462.

Graf, P., and Schacter, D. L. (1985). Implicit and explicit memory for new associations in normal and amnesic subjects. J. Exp. Psychol. Learn. Mem. Cogn. 11, 501-518.

Graham, K. S., Barense, M. D., and Lee, A. C. (2010). Going beyond LTM in the MTL: a synthesis of neuropsychological and neuroimaging findings on the role of the medial temporal lobe in memory and perception. Neuropsychologia 48, 831-853.

Greene, A. J., Gross, W. L., Elsinger, C. L., and Rao, S. M. (2006) An fMRI analysis of the human hippocampus: inference, context, and task awareness. J. $\operatorname{Cog}$. Neurosci. 18, 1156-1173.

Greene, A. J., Spellman, B. A., Dusek, J. A., Eichenbaum, H. B., and Levy, W B. (2001). Relational learning with and without awareness: transitive inference using nonverbal stimuli in humans. Mem. Cognit. 29, 893-902.

Hannula, D. E., Althoff, R. R., Warren, D. E., Riggs, L., Cohen, N. J., and Ryan, J. D. (2010). Worth a glance: using eye movements to investigate the cognitive neuroscience of memory. Front. Hum. Neurosci. 4:166 doi: 10.3389/fnhum.2010.00166

Hannula, D. E., and Greene, A. J. (2012). The hippocampus reevaluated in unconscious learning and memory: at a tipping point? Front Hum. Neurosci. 6:80. doi: 10.3389/ fnhum.2012.00080

Hannula, D. E., and Ranganath, C. (2009). The eyes have it: hippocampal activity predicts expression of memory in eye movements. Neuron $63,592-599$.

Hannula, D. E., Ryan, J. D., Tranel, D., and Cohen, N. J. (2007). Rapid onset relational memory effects are evident in eye movement behavior but not in hippocampal amnesia. J. Cogn. Neurosci. 19, 1690-1705.

Hannula, D. E., Tranel, D., and Cohen, N. J. (2006). The long and the short of it: relational memory impairments in amnesia, even at short lags. J. Neurosci. 26, 8352-8359.

Hartley, T., Bird, C. M., Chan, D., Cipolotti, L., Husain, M., VarghaKhadem, F., and Burgess, N. (2007). The hippocampus is required for short-term topographical memory in humans. Hippocampus 17, 34-48.

Hasselmo, M. E. (2005). The role of hippocampal regions CA3 and CA1 in matching entorhinal input with retrieval of associations between objects and context: theoretical comment on Lee et al. (2005). Behav. Neurosci. 119, 342-345.

Hasselmo, M. E., and Wyble, B. P. (1997). Free recall and recognition in a network model of the hippocampus: simulating effects of scopolamine on human memory function. Behav. Brain Res. 89, 1-34.
Hayhoe, M. M., Bensinger, D. G., and Ballard, D. H. (1998). Task constraints in visual working memory. Vis. Res. 38, 125-137.

Henderson, J. M., and Hollingworth, A. (2003). Eye movements and visual memory: detecting changes to saccade targets in scenes. Percept. Psychophys. 65, 58-71.

Henke, K. (2010). A model for memory systems based on processing modes rather than consciousness. Nat. Rev. Neurosci. 11, 523-532.

Hollingworth, A. (2007). Objectposition binding in visual memory for natural scenes and object arrays. J. Exp. Psychol. Hum. Percept. Perform. 33, 31-47.

Hollingworth, A. (2009). Two forms of scene memory guide visual search: memory for scene context and memory for the binding of target object to scene location. Vis. Cogn. 17, 273-291.

Hollingworth, A., and Henderson, J. M. (2002). Accurate visual memory for previously attended objects in natural scenes. J. Exp. Psychol. Hum. Percept. Perform. 28, 113-136.

Hollingworth, A., Richard, A. M., and Luck, S. J. (2008). Understanding the function of visual short-term memory: transsaccadic memory, object correspondence, and gaze correction. J. Exp. Psychol. Gen. 137, 163-181.

Hollingworth, A., Williams, C. C., and Henderson, J. M. (2001). To see and remember: visually specific information is retained in memory from previously attended objects in natural scenes. Psychon. Bull. Rev. 8 761-768.

Jeneson, A., Mauldin, K. N., Hopkins, R. O., and Squire, L. R. (2011). The role of the hippocampus in retaining relational information across short delays: the importance of memory load. Learn. Mem. 18, 301-305.

Jeneson, A., Mauldin, K. N., and Squire, L. R. (2010). Intact working memory for relational information after medial temporal lobe damage. J. Neurosci. 30, 13624-13629.

Jensen, O., and Lisman, J. E. (1996) Hippocampal CA3 region predicts memory sequences: accounting for the phase precession of place cells. Learn. Mem. 3, 279-287.

Kesner, R. P. (1989). Retrospective and prospective coding of information: role of the medial prefrontal cortex. Exp. Brain Res. 74, 163-167.

Kesner, R. P., Bolland, B. L., and Dakis, M. (1993). Memory for spatial locations, motor responses, and objects: triple dissociation among the hippocampus, caudate nucleus, and 
extrastriate visual cortex. Exp. Brain Res. 93, 462-470.

Konkel, A., and Cohen, N. J. (2009). Relational memory and the hippocampus: representations and methods. Front. Neurosci. 3, 166-174. doi: 10.3389/ neuro.01.023.2009

Konkel, A., Warren, D. E., Duff, M. C., Tranel, D. N., and Cohen, N. J. (2008). Hippocampal amnesia impairs all manner of relational memory. Front. Hum. Neurosci. 2:15. doi: 10.3389/neuro. 09.015.2008

Kumaran, D., and Maguire, E. A. (2006). An unexpected sequence of events: mismatch detection in the human hippocampus. PLoS Biol. 4:e424. doi: 10.1371/journal.pbio.0040424

Kumaran, D., and Maguire, E. A. (2007). Which computational mechanisms operate in the hippocampus during novelty detection? Hippocampus 17, 735-748.

Lavenex, P., and Amaral, D. G. (2000). Hippocampal-neocortical interaction: a hierarchy of associativity. Hippocampus 10, 420-430.

Lee, A. C., Buckley, M. J., Pegman, S. J., Spiers, H., Scahill, V. L., Gaffan, D., Bussey, T. J., Davies, R. R., Kapur, N., Hodges, J. R., and Graham, K. S. (2005a). Specialization in the medial temporal lobe for processing of objects and scenes. Hippocampus 15, 782-797.

Lee, A. C., Bussey, T. J., Murray, E. A., Saksida, L. M., Epstein, R. A., Kapur, N., Hodges, J. R., and Graham, K. S. (2005b). Perceptual deficits in amnesia: challenging the medial temporal lobe 'mnemonic' view. Neuropsychologia 43, 1-11.

Lee, A. C. H., Yeung, L.-K., and Barense, M. D. (2012). The hippocampus and visual perception. Front. Hum. Neurosci. 6:91. doi: 10.3389/fnhum.2012.00091

Lee, A. C., Scahill, V. L., and Graham, K. S. (2008). Activating the medial temporal lobe during oddity judgment for faces and scenes. Cereb. Cortex 18, 683-696.

Lee, I., and Kesner, R. P. (2003). Differential roles of dorsal hippocampal subregions in spatial working memory with short versus intermediate delay. Behav. Neurosci. 117, 1044-1053.

Lee, I., Hunsaker, M. R., and Kesner, R. P. (2005). The role of hippocampal subregions in detecting spatial novelty. Behav. Neurosci. 119, 145-153.

Lisman, J. E., and Grace, A. A. (2005). The hippocampal-VTA loop: controlling the entry of information into long-term memory. Neuron 46, 703-713.

MacDonald, C. J., Lepage, K. Q., Eden, U. T., and Eichenbaum, H. (2011). Hippocampal "time cells" bridge the gap in memory for discontiguous events. Neuron 71, 737-749.

Manns, J. R., and Squire, L. R. (2001). Perceptual learning, awareness, and the hippocampus. Hippocampus 11, 776-782.

Mayes, A., Montaldi, D., and Migo, E. (2007). Associative memory and the medial temporal lobes. Trends Cogn. Sci. 11, 126-135.

McGlinchey-Berroth, R., Carrillo, M. C., Gabrieli, J. D., Brawn, C. M., and Disterhoft, J. F. (1997). Impaired trace eyeblink conditioning in bilateral, medial-temporal lobe amnesia. Behav. Neurosci. 111, 873-882.

Meeter, M., Murre, J. M., and Talamini, L. M. (2004). Mode shifting between storage and recall based on novelty detection in oscillating hippocampal circuits. Hippocampus 14, 722-741.

Meunier, M., Bachevalier, J., Mishkin, M., and Murray, E. A. (1993). Effects on visual recognition of combined and separate ablations of the entorhinal and perirhinal cortex in rhesus monkeys. J. Neurosci. 13, 5418-5432.

Milner, B. (1962) "Les troubles de la memoire accompagnant des lesions hippocampiques bilaterales," in Physiologie de l'Hippocampe, ed P. Passouant (Paris: Colloques Internationaux), 257-272.

Mormann, F., Kornblith, S., Quiroga, R. Q., Kraskov, A., Cerf, M., Fried, I., and Koch, C. (2008). Latency and selectivity of single neurons indicate hierarchical processing in the human medial temporal lobe. J. Neurosci. 28, 8865-8872.

Moses, S. N., and Ryan, J. D. (2006). A comparison and evaluation of the predictions of relational and conjunctive accounts of hippocampal function. Hippocampus 16, 43-65.

Moses, S. N., Winocur, G., Ryan, J. D., and Moscovitch, M. (2007). Environmental complexity affects contextual fear conditioning following hippocampal lesions in rats. Hippocampus 17, 333-337.

Moyer, J. R. Jr., Deyo, R. A., and Disterhoft, J. F. (1990). Hippocampectomy disrupts trace eye-blink conditioning in rabbits. Behav. Neurosci. 104, 243-252.

Murray, E. A., and Bussey, T. J. (1999). Perceptual-mnemonic functions of the perirhinal cortex. Trends Cogn. Sci. 3, 142-151.

Murray, E. A., and Mishkin, M. (1998). Object recognition and location memory in monkeys with excitotoxic lesions of the amygdala and hippocampus. J. Neurosci. 18 6568-6582.

Nadel, L., and Moscovitch, M. (1997). Memory consolidation, retrograde amnesia and the hippocampal complex. Curr. Opin. Neurobiol. 7 , 217-227.

Nemanic, S., Alvarado, M. C. and Bachevalier, J. (2004). The hippocampal/parahippocampal regions and recognition memory: insights from visual paired comparison versus object-delayed nonmatching in monkeys. J. Neurosci. 24, 2013-2026.

Nichols, E. A., Kao, Y. C., Verfaellie, M., and Gabrieli, J. D. (2006). Working memory and long-term memory for faces: evidence from fMRI and global amnesia for involvement of the medial temporal lobes. Hippocampus 16, 604-616.

Norman, K. A., and O'Reilly, R. C. (2003). Modeling hippocampal and neocortical contributions to recognition memory: a complementarylearning-systems approach. Psychol. Rev. 110, 611-646.

O'Keefe, J., and Nadel, L. (1978). The Hippocampus as a Cognitive Map. New York, NY: Oxford University Press.

Olson, I. R., Page, K., Moore, K. S., Chatterjee, A., and Verfaellie, M. (2006a). Working memory for conjunctions relies on the medial temporal lobe. J. Neurosci. 26, 4596-4601.

Olson, I. R., Moore, K. S., Stark, M., and Chatterjee, A. (2006b). Visual working memory is impaired when the medial temporal lobe is damaged. J. Cogn. Neurosci. 18 1087-1097.

Olsen, R. K., Nichols, E. A., Chen, J., Hunt, J. F., Glover, G. H. Gabrieli, J. D., and Wagner, A D. (2009). Performance-related sustained and anticipatory activity in human medial temporal lobe during delayed match-to-sample. J. Neurosci. 29, 11880-11890.

Olton, D. S., Becker, J. T., and Handelmann, G. E. (1979). Hippocampus, space and memory. Behav. Brain Sci. 2, 313-365.

Otto, T., and Eichenbaum, H. (1992). Complementary roles of the orbital prefrontal cortex and the perirhinal-entorhinal cortices in an odor-guided delayed-nonmatchingto-sample task. Behav. Neurosci. 106, 762-775.

Penfield, W., and Milner, B. (1958). Memory deficit produced by bilateral lesions in the hippocampal zone. AMA Arch. Neurol. Psychiatry 79, 475-497.

Piekema, C., Fernandez, G., Postma, A., Hendriks, M. P., Wester, A. J. and Kessels, R. P. (2007). Spatial and non-spatial contextual working memory in patients with diencephalic or hippocampal dysfunction. Brain Res. 1172, 103-109.

Piekema, C., Kessels, R. P., Mars, R. B., Petersson, K. M., and Fernandez, G. (2006). The right hippocampus participates in short-term memory maintenance of object-location associations. Neuroimage 33, 374-382.

Prisko, L.-H. (1963). Short-Term Memory in Focal Cerebral Damage. Montreal, QC: McGill University.

Prusky, G. T., Douglas, R. M., Nelson, L., Shabanpoor, A., and Sutherland, R. J. (2004). Visual memory task for rats reveals an essential role for hippocampus and perirhinal cortex. Proc. Natl. Acad. Sci. U.S.A. 101, 5064-5068.

Quiroga, R. Q., Reddy, L., Kreiman, G., Koch, C., and Fried, I. (2005). Invariant visual representation by single neurons in the human brain. Nature 435, 1102-1107.

Ranganath, C., Cohen, M. X., and Brozinsky, C. J. (2005). Working memory maintenance contributes to long-term memory formation: neural and behavioral evidence. J. Cogn. Neurosci. 17, 994-1010.

Ranganath, C., and D'Esposito, M. (2001). Medial temporal lobe activity associated with active maintenance of novel information. Neuron 31, 865-873.

Reder, L. M., Park, H., and Kieffaber, P. D. (2009). Memory systems do not divide on consciousness: reinterpreting memory in terms of activation and binding. Psychol. Bull. 135, 23-49.

Riggs, L., Moses, S. N., Bardouille, T., Herdman, A. T., Ross, B., and Ryan, J. D. (2009). A complementary analytic approach to examining medial temporal lobe sources using magnetoencephalography. Neuroimage 45, 627-642.

Rose, N. S., Olsen, R. K., Craik, F. I., and Rosenbaum, R. S. (2012). Working memory and amnesia: the role of stimulus novelty. Neuropsychologia 50, 11-18.

Rosenbaum, R. S., Priselac, S., Kohler, S., Black, S. E., Gao, F., Nadel, L. and Moscovitch, M. (2000). Remote spatial memory in an amnesic person with extensive bilateral hippocampal lesions. Nat. Neurosci. 3, 1044-1048.

Rutishauser, U., Ross, I. B., Mamelak, A. N., and Schuman, E. M. (2010). 
Human memory strength is predicted by theta-frequency phaselocking of single neurons. Nature 464, 903-907.

Ryan, J. D., Althoff, R. R., Whitlow, S., and Cohen, N. J. (2000). Amnesia is a deficit in relational memory. Psychol. Sci. 11, 454-461.

Ryan, J. D., and Cohen, N. J. (2003). Evaluating the neuropsychological dissociation evidence for multiple memory systems. Cogn. Affect. Behav. Neurosci. 3, 168-185.

Ryan, J. D., and Cohen, N. J. (2004a). Processing and short-term retention of relational information in amnesia. Neuropsychologia 42, 497-511.

Ryan, J. D., and Cohen, N. J. (2004b). The nature of change detection and online representations of scenes. J. Exp. Psychol. Hum. Percept. Perform. 30, 988-1015.

Ryan, J. D., Moses, S. N., Ostreicher, M. L., Bardouille, T., Herdman, A. T., Riggs, L., and Tulving, E. (2008). Seeing sounds and hearing sights: the influence of prior learning on current perception. J. Cogn. Neurosci. 20, 1030-1042.

Schacter, D. L. (1987). Implicit expressions of memory in organic amnesia: learning of new facts and associations. Hum. Neurobiol. 6, 107-118.

Scoville, W. B., and Milner, B. (1957). Loss of recent memory after bilateral hippocampal lesions. J. Neurol. Neurosurg. Psychiatr. 20, 11-21.

Shrager, Y., Levy, D. A., Hopkins, R. O., and Squire, L. R. (2008) Working memory and the organization of brain systems. J. Neurosci. 28, 4818-4822.

Sidman, M., Stoddard, L. T., and Mohr, J. P. (1968). Some additional quantitative observations of immediate memory in a patient with bilateral hippocampal lesions. Neuropsychologia 6, 245-254.

Smith, C., and Squire, L. R. (2005). Declarative memory, awareness, and transitive inference. J. Neurosci. 25, 10138-10146.

Sperling, R. A., Bates, J. F., Cocchiarella, A. J., Schacter, D. L., Rosen, B. R., and Albert, M. S. (2001). Encoding novel face-name associations: a functional MRI study. Hum. Brain Mapp. 14, 129-139.

Squire, L. R. (1992). Memory and the hippocampus: a synthesis from findings with rats, monkeys, and humans. Psychol. Rev. 99, 195-231.

Squire, L. R., and Alvarez, P. (1995). Retrograde amnesia and memory consolidation: a neurobiological perspective. Curr. Opin. Neurobiol. 5, 169-177.

Staresina, B. P., and Davachi, L. (2006). Differential encoding mechanisms for subsequent associative recognition and free recall. J. Neurosci. 26, 9162-9172.

Staresina, B. P., and Davachi, L. (2008). Selective and shared contributions of the hippocampus and perirhinal cortex to episodic item and associative encoding. J. Cogn. Neurosci. 20, 1478-1489.

Staresina, B. P., and Davachi, L. (2010). Object unitization and associative memory formation are supported by distinct brain regions. J. Neurosci. 30, 9890-9897.

Suzuki, W. A., and Amaral, D. G. (1994a). Perirhinal and parahippocampal cortices of the macaque monkey: cortical afferents. J. Comp. Neurol. 350, 497-533.

Suzuki, W. A., and Amaral, D. G. (1994b). Topographic organization of the reciprocal connections between the monkey entorhinal cortex and the perirhinal and parahippocampal cortices. J. Neurosci. 14(3 Pt 2), 1856-1877.

Thorpe, S., Fize, D., and Marlot, C. (1996). Speed of processing in the human visual system. Nature 381, 520-522.

Toepper, M., Markowitsch, H. J., Gebhardt, H., Beblo, T., Thomas,
C., Gallhofer, B., Driessen, M., and Sammer, G. (2010). Hippocampal involvement in working memory encoding of changing locations: an fMRI study. Brain Res. 1354, 91-99.

VanRullen, R., and Thorpe, S. J. (2001) The time course of visual processing: from early perception to decision-making. J. Cogn. Neurosci. 13, 454-461.

Vinogradova, O. S. (2001). Hippocampus as comparator: role of the two input and two output systems of the hippocampus in selection and registration of information. Hippocampus 11, 578-598.

Warren, D. E., Duff, M. C., Tranel, D., and Cohen, N. J. (2011). Observing degradation of visual representations over short intervals when medial temporal lobe is damaged J. Cogn. Neurosci. 23, 3862-3873.

Warrington, E. K. (1981) "The double dissociation of short and longterm memory deficits," in Human Memory and Amnesia. ed L. S. Cermak (Hillsdale, NJ: Lawrence Erlbaum), 61-74.

Warrington, E. K., and Baddeley, A D. (1974). Amnesia and memory for visual location. Neuropsychologia 12, 257-263.

Warrington, E. K., and Taylor, A M. (1973). Immediate memory for faces: long- or short-term memory? Q. J. Exp. Psychol. 25, 316-322.

Weiss, C., Bouwmeester, H., Power, J. M., and Disterhoft, J. F. (1999) Hippocampal lesions prevent trace eyeblink conditioning in the freely moving rat. Behav. Brain Res. 99, 123-132.

Wickelgren, W. A. (1968). Sparing of short-term memory in an amnestic patient: implications for strenght theory of memory. Neuropsychologia 6, 10.

Winocur, G., and Moscovitch, M. (1990). Hippocampal and prefrontal cortex contributions to learning and memory: analysis of lesion and aging effects on maze learning in rats. Behav. Neurosci. 104, 544-551.

Yanike, M., Wirth, S., and Suzuki, W. A. (2004). Representation of welllearned information in the monkey hippocampus. Neuron 42, 477-487.

Yarbus, A. L. (1967). Eye Movements and Vision. New York, NY: Plenum Press.

Zeineh, M. M., Engel, S. A., Thompson, P. M., and Bookheimer, S. Y. (2003). Dynamics of the hippocampus during encoding and retrieval of face-name pairs. Science 299, 577-580.

Zola-Morgan, S., Squire, L. R., Amaral, D. G., and Suzuki, W. A. (1989). Lesions of perirhinal and parahippocampal cortex that spare the amygdala and hippocampal formation produce severe memory impairment. J. Neurosci. 9, 4355-4370.

Conflict of Interest Statement: The authors declare that the research was conducted in the absence of any commercial or financial relationships that could be construed as a potential conflict of interest.

Received: 15 October 2011; accepted: 08 May 2012; published online: 25 May 2012.

Citation: Olsen RK, Moses SN, Riggs $L$ and Ryan JD (2012) The hippocampus supports multiple cognitive processes through relational binding and comparison. Front. Hum. Neurosci. 6:146. doi: 10.3389/fnhum.2012.00146

Copyright (C) 2012 Olsen, Moses, Riggs and Ryan. This is an open-access article distributed under the terms of the Creative Commons Attribution Non Commercial License, which permits noncommercial use, distribution, and reproduction in other forums, provided the original authors and source are credited. 